RESENHA

\title{
Serviço Social global em um contexto político: perspectivas radicais
}

Global social work in a political context: radical perspectives

\section{Roberta UCHÔA*}

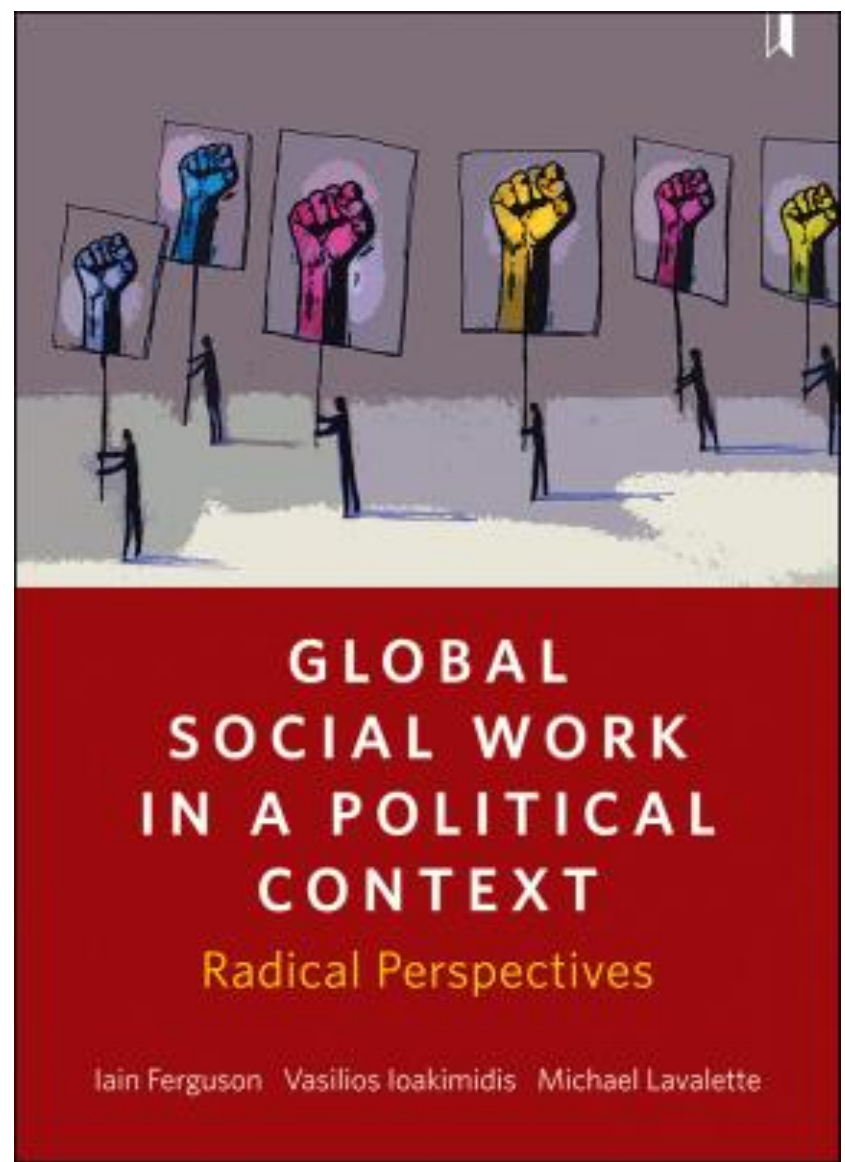

\section{RESENHA/ BOOK REVIEW}

FERGUSON, Iain; IOAKIMIDIS, Vasilios; LAVALETTE, Michael. Global social work in a political context: Radical perspectives. Bristol: Policy Press, 2018. 210 p.

\footnotetext{
* Assistente Social. Phd in Sociology of Addiction. Professora do Curso de Graduação em Serviço Social, da Universidade Federal de Pernambuco (UFPE, Recife, Brasil). Rua Professor Gondim Filho, no. 71/31, Boa Viagem, Recife, PE, CEP.: 51111-120. E-mail: <rsuchoa@uol.com.br>. ORC ID: <http://orcid.org/ oooo0002-5473-657X>.
} 


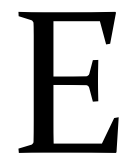

$\mathrm{m}$ janeiro/2018, recebi com muita alegria, o convite de Iain Ferguson para fazer a resenha do livro Global Social Work in a Political Context: Radical perspectives, escrito por ele, em parceria com Vasilios Ioakimidis e Michael Lavalette. Posteriormente, o convite foi endossado por Maria Lúcia Garcia, editora da Revista Argumentum. Iain e Michael são escoceses e Vasilios é de origem grega. Os três atuam como docentes na área de Serviço Social em diferentes universidades britânicas (West of Scotland, Hope Liverpool e Essex, respectivamente) com pesquisas em diversos campos, a exemplo de serviço social e políticas sociais, neoliberalismo, Palestina e juventude, e serviço social em situações extremas e/ou de conflitos, como as guerras. Eles foram fundadores do grupo Social Work Action Network (SWAN), que reúne assistentes sociais radicais em países como Irlanda, Grécia, Canadá e Grã-Bretanha. Iain e Michael são editores do periódico Critical and Radical Social Work - An International Journal, uma publicação da Policy Press, Universidade de Bristol, que divulga artigos sobre os impactos do neoliberalismo na seguridade social, o debate acerca da definição do serviço social e as práticas do serviço social no mundo. Mas o mais importante é que, tomando emprestada a expressão do mestre José Paulo Netto, um fio vermelho os une a todos e a nós do serviço social brasileiro: a tradição Marxista. Esta ligação é inclusive saudada pelos autores logo no primeiro parágrafo dos Agradecimentos do livro:

Em particular, nos lembramos com afeição da reunião coordenada por nós na Conferência Global de Serviço Social na Suécia para juntos tentar estabelecer uma rede internacional; a reunião teve uma boa presença e quando estava para começar os colegas brasileiros chegaram. A presença deles foi extraordinária por dois motivos: Primeiro, eles eram muitos! Segundo, todos eles queriam debater conosco sobre a permanente relevância do Marxismo para o serviço social - algo que não vemos tão frequentemente!

Esse encontro foi tão extraordinário para eles como provavelmente para a maioria dos assistentes sociais brasileiros presentes naquela reunião em Estocolmo (2012), pois nas conferências internacionais de serviço social também é rara a presença de colegas estrangeiros e a apresentação de trabalhos no campo da tradição Marxista.

Portanto, não causou nenhuma surpresa que a teoria social crítica e a perspectiva crítica do serviço social tenham sido os fios condutores nesse livro escrito por esses autores. Temas como crise da social democracia; novos movimentos sociais de contestação do poder dos poderosos; crescimento político de grupos de extrema direita; direitos dos refugiados e mudanças climáticas são analisados sob o contexto da longa depressão, da duradoura instabilidade financeira e do baixo crescimento econômico mundial no qual se acirram as políticas de austeridade impostas pelo capital para restaurar suas taxas de lucro e rebaixar as condições de vida da maioria da população. Como fica o serviço social diante desses problemas e como a profissão deve responder? Estas difíceis questões são os principais desafios postos pelos autores.

Além do suporte da economia política, o livro é marcado pelo internacionalismo. Os autores trazem mais de 20 anos de experiências colaborando com práticas do serviço social crítico em países como Grã-Bretanha, Irlanda, Grécia, Canadá, Estados Unidos (particularmente, Boston), Suécia, Hungria, Hong Kong, Espanha, África do Sul, Nova Zelândia e vários países da América Latina, inclusive o Brasil. Aliás, o Brasil aparece em todos os capítulos que

Argum., Vitória, v. 10, n. 2, p. 242-244, maio/ago. 2018. 
estruturam o livro, com destaque à parte que trata do presente e do passado do serviço social no mundo. As contribuições do serviço social brasileiro, em especial no movimento de reconceituação latino americano nas décadas de 1960 e 1970 e na discussão contemporânea sobre a definição global da profissão, evidenciam que os autores mantêm grande interesse no Brasil e estreita colaboração com profissionais e grupos de pesquisas no campo do serviço social crítico brasileiro, desde aquele encontro em Estocolmo.

Outro importante destaque a ser dado, refere-se à inestimável obra do educador pernambucano, Paulo Freire, e sua influência sobre assistentes sociais e educadores populares na América Latina e em outros países em desenvolvimento. Em tempos de golpes 'modernos' de Estado, seja parlamentar, jurídico, midiático, militar, econômico e/ou social, no qual ganham força o conservadorismo e o obscurantismo religioso, evidenciados no Brasil em projetos como Escola sem Partido e na tentativa de destituição de Paulo Freire, como patrono da educação brasileira, destacar a filosofia da práxis como referência de diversos movimentos sociais no mundo, é a melhor evidência de que os homens podem ser presos, mas suas ideias jamais podem ser aprisionadas.

Por fim, em suas conclusões, os autores apontam alguns elementos constitutivos do que chamam "o novo radicalismo do serviço social”, a exemplo de posição contrária ao mercado: pessoas antes do lucro; do estabelecimento de vínculo mais estreito e horizontal com usuários; do trabalho de desenvolvimento de comunidade com participação direta nos movimentos sociais, populares e sindicais; e de construção de alianças entre trabalhadores, academia, usuários, movimentos sociais e sindicatos. Para transpor limitações das práticas locais, utilizando a Internet e as mídias sociais, eles reforçam a importância do estabelecimento de redes globais para conhecer a realidade dos diferentes países e para a troca de experiências entre profissionais, acadêmicos, usuários e militantes. Mas não se trata apenas de troca de informações. Trata-se, sobretudo, de demonstração de solidariedade. Iain, Vasilios e Michael advogam que a solidariedade deve ser o valor central do serviço social, de forma que se reafirme nossa natureza social, nossa humanidade, para se confrontar ao racismo, à xenofobia e aos individualismos tão característicos do neoliberalismo. A crise global exige soluções globais pautadas na solidariedade internacional e mudanças sociais.

\section{Roberta UCHÔA}

Assistente Social. PhD in Sociology of Addiction. Professora do Curso de Graduação em Serviço Social e Coordenadora do Grupo de Estudos sobre Álcool e outras Drogas, da Universidade Federal de Pernambuco.

Argum., Vitória, v. 10, n. 2, p. 242-244, maio/ago. 2018. 